\title{
SR-BI protects against endotoxemia in mice through its roles in glucocorticoid production and hepatic clearance
}

\author{
Lei Cai, Ailing Ji, Frederick C. de Beer, Lisa R. Tannock, \\ and Deneys R. van der Westhuyzen

\begin{abstract}
Division of Endocrinology and Molecular Medicine, Department of Internal Medicine, Cardiovascular Research Center, and Graduate Center of Nutritional Sciences, University of Kentucky Medical Center, Lexington, Kentucky, USA.

Veterans Affairs Medical Center, Lexington, Kentucky, USA.
\end{abstract}

\begin{abstract}
Septic shock results from an uncontrolled inflammatory response, mediated primarily by LPS. Cholesterol transport plays an important role in the host response to LPS, as LPS is neutralized by lipoproteins and adrenal cholesterol uptake is required for antiinflammatory glucocorticoid synthesis. In this study, we show that scavenger receptor B-I (SR-BI), an HDL receptor that mediates HDL cholesterol ester uptake into cells, is required for the normal antiinflammatory response to LPS-induced endotoxic shock. Despite elevated plasma HDL levels, SR-BI-null mice displayed an uncontrollable inflammatory cytokine response and a markedly higher lethality rate than control mice in response to LPS. In addition, SR-BI-null mice showed a lack of inducible glucocorticoid synthesis in response to LPS, bacterial infection, stress, or ACTH. Glucocorticoid insufficiency in SR-BI-null mice was due to primary adrenal malfunction resulting from deficient cholesterol delivery from HDL. Furthermore, corticosterone supplementation decreased the sensitivity of SR-BI-null mice to LPS. Plasma from control and SR-BI-null mice exhibited a similar ability to neutralize LPS, whereas SR-BI-null mice showed decreased plasma clearance of LPS into the liver and hepatocytes compared with normal mice. We conclude that SR-BI in mice is required for the antiinflammatory response to LPS-induced endotoxic shock, likely through its essential role in facilitating glucocorticoid production and LPS hepatic clearance.
\end{abstract}

\section{Introduction}

Endotoxic shock remains a significant cause of death despite the use of various therapeutic approaches (1). LPS is the primary cause of Gram-negative sepsis. LPS, through its interaction with the LPS-binding protein-containing (LBP-containing) LBPCD14-TLR4 complex, activates macrophages, causing the release of inflammatory cytokines (2). While the inflammatory response represents a host defense to invading pathogens, uncontrolled systemic inflammation can lead to serious systemic complications such as disseminated intravascular coagulation, tissue damage, and endotoxic shock (2).

LPS can be neutralized by the major lipoproteins, HDL, LDL, VLDL, and chylomicrons as well as apolipoproteins apoE and apoA-I (3-5). apoE may protect by redirecting LPS from Kupffer cells to hepatocytes (3). The preferential binding of LBP to HDL accounts for HDL being the primary carrier of LPS in the blood (6). While LPS is cleared mainly by hepatocytes, the mechanism or mechanisms are unclear. Although scavenger receptor A (SR-A) has been reported to mediate LPS uptake and detoxification (7), SR-A-null mice showed unchanged production of TNF- $\alpha$ in response to LPS (8), casting doubt on the physiological role of SR-A in sepsis. These findings suggest the involvement of other scavenger receptors, such as scavenger receptor B-I (SR-BI), in LPS metabolism.

Nonstandard abbreviations used: CE, cholesterol ester; Cyp11A1, cytochrome P450 side-chain cleavage enzyme; LAL, Limulus amebocyte lysate; LBP, LPS-binding protein; LDLR, LDL receptor; MCP-1, monocyte chemoattractant protein-1; Q-PCR, quantitative real-time PCR analysis; SR-A, scavenger receptor A; SR-BI, scavenger receptor B-I; StAR, steroidogenic acute regulatory protein.

Conflict of interest: The authors have declared that no conflict of interest exists. Citation for this article: J. Clin. Invest. 118:364-375 (2008). doi:10.1172/JCI31539.
SR-BI is an HDL receptor that plays a key role in the reverse cholesterol transport pathway through mediating selective lipid uptake from HDL particles $(9,10)$. SR-BI in the liver is highly expressed in hepatocytes (9) and to a lesser extent in Kupffer cells (11) and functions to clear HDL cholesterol into the bile (12). Studies using SR-BI-deficient and -transgenic mice have shown that SR-BI is protective against atherosclerosis (10). SR-BI has a broad ligand-binding specificity and is involved in the binding and cellular uptake of various endogenous ligands, such as $\beta$-amyloid and serum amyloid A (13), apoptotic cells, and exogenous pathogens (10). For example, SR-BI plays a role as a receptor for hepatitis $C$ virus and is required for virus infection (14). Importantly, SR-BI also mediates the binding and uptake of LPS (15), the major Gram-negative bacterial cell wall component, in macrophages and HeLa cells overexpressing SR-BI, and lipoteichoic acid (LTA) (16), a component of Gram-positive bacteria. Furthermore, SR-BI and its alternatively spliced variant, SR-BII (17), have been shown to directly bind a variety of bacteria with little discrimination, suggesting a conserved role for these receptors in pattern recognition and innate immunity (18). This is supported by the fact that SR-BI-null mice are more susceptible to LPS-induced death, a finding attributed to a protective effect of SR-BI in inhibiting NOinduced cell toxicity (19). A recent study, however, reported that SR-BI facilitates bacterial invasion and proliferation in cells, with evasion of lysosomal processing (16), indicating that SR-BI might facilitate bacterial infection and sepsis.

SR-BI is highly expressed in the adrenals, ovary, and testis, where it functions to provide cholesterol for steroid hormone synthesis through the selective cholesterol ester (CE) uptake from HDL and LDL (20-22). Although the LDL receptor (LDLR) also contributes 
A

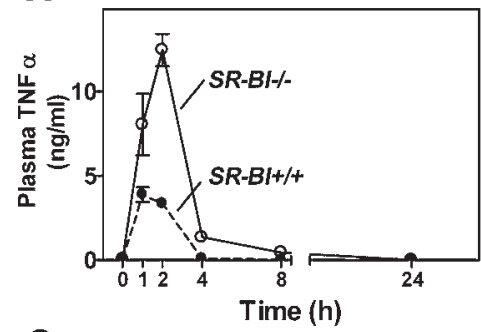

C



B

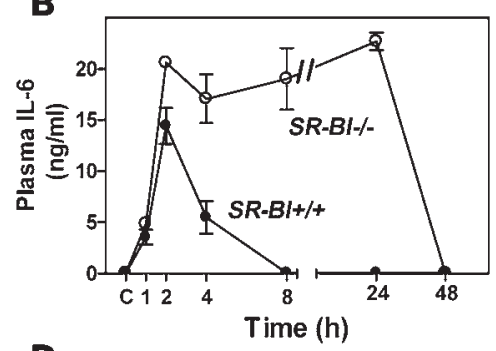

D

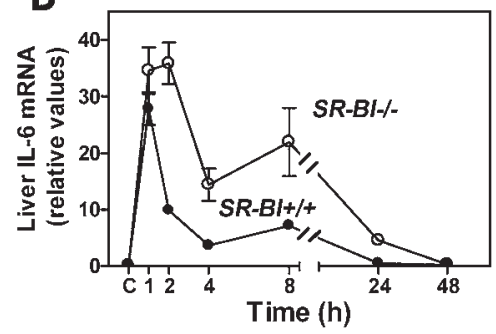

Figure 1

Hyperinflammatory response in $S R-B I^{-/-}$mice challenged with LPS. SR-BI-/- and $S R-B I^{+/+}$mice were injected i.p. with $0.5 \mu \mathrm{g} / \mathrm{g}$ body weight of LPS. Plasma TNF- $\alpha$ and IL- 6 levels were determined by ELISA (A and B). Liver TNF- $\alpha$ and IL-6 mRNA levels were determined by Q-PCR (C and $\mathbf{D})$. Values shown are the mean $\pm \operatorname{SD}(n=3)$. Similar results were found in 4 independent experiments. to cholesterol delivery through LDL uptake (23), SR-BI-mediated HDL cholesterol uptake appears to be the major source of cholesterol for glucocorticoid synthesis in rodents $(20,24,25)$. A critical role of SR-BI in humans is suggested by the observation that patients with familial hypercholesterolemia that lack functional LDLR show a normal response to ACTH (26). Glucocorticoids exert antiinflammatory effects by suppressing proinflammatory cytokines (e.g. TNF- $\alpha$, IL-1, IL-6) and stimulating antiinflammatory mediators (IL-10, TGF- $\beta$ ) (27). Adrenal deficiency, characterized by glucocorticoid insufficiency, is often associated with sepsis (28). Common causes of adrenal failure are impaired function of the upstream hypothalamic-pituitary-adrenal axis (secondary adrenal insufficiency) and malfunction or destruction of the adrenal glands (primary adrenal insufficiency). Since only small amounts of glucocorticoids are stored in the adrenals (29), primary adrenal failure in endotoxic shock is usually due to insufficient glucocorticoid biosynthesis (29). Depletion of plasma HDL in apoA-I-null mice (30) or by inactivation of SR-BI (31) markedly reduces CE content in the adrenals. In the case of apoA-I-null mice, adrenal function was affected and corticosterone production was limited (30). In SR-BI-null mice, adrenal function appeared unaffected under normal physiological conditions (10).

In this study, we have investigated the role of SR-BI in regulating LPS-induced inflammation and endotoxic shock. Studies using control and SR-BI-null mice have shown that SR-BI expression is essential for stimulated glucocorticoid production in the adrenals in response to LPS and stress, and that glucocorticoid insufficiency as well as reduced LPS clearance likely contribute to the enhanced inflammation and endotoxin-induced death in SR-BI-null mice.

\section{Results}

SR-BI-null mice show an exaggerated inflammatory response to LPSinduced endotoxic shock. To determine the influence of SR-BI on LPS-induced inflammation, SR-BI-null and control mice were injected i.p. with LPS $(0.5 \mu \mathrm{g} / \mathrm{g}$ body weight), and serum cytokine levels were determined by ELISA at various times following injection. As shown in Figure 1, LPS resulted in a strong induction of both TNF- $\alpha$ and IL- 6 . In the case of TNF- $\alpha$, maximum concentrations were reached by 2 hours and were markedly higher in the SR-BI-null mice than in control mice (Figure 1A). In the case of IL-6, LPS-induced plasma concentrations reached nearly similar maximal levels in both SR-BI-null and control mice after 2 hours (Figure 1B). However, IL-6 levels in control mice returned to baseline levels after 8 hours, whereas the level of IL-6 in SR-BInull mice remained elevated for 24 hours before dropping to baseline levels by 48 hours. An increased TNF- $\alpha$ and IL- 6 cytokine response in SR-BI-null mice compared with control mice was evident at each LPS concentration tested, and no cytokine induction was observed in mice injected with saline alone (data not shown). TNF- $\alpha$ and IL- 6 expression in the livers of these mice were assessed by quantitative real-time PCR analysis (Q-PCR) of mRNA levels. In line with the observed differences in protein expression, SR-BI-null mice had higher expression of liver mRNA for both TNF- $\alpha$ and IL- 6 in response to LPS than control mice (Figure $1, \mathrm{C}$ and D). However, the lack of close correlation between liver mRNA levels and plasma cytokine levels suggests posttranscriptional regulation mechanisms and/or the contribution of nonhepatic cytokine production.

A cytokine array analysis of plasma at either 2 or 24 hours after LPS injection showed that the levels of a variety of proinflammatory cytokines were increased to a significantly greater extent in SR-BI-null mice compared with control mice (Table 1). Cytokines that showed no difference between SR-BI-null and control mice at 2 hours are also listed in Table 1. Of these, IL-5, IL-6, and IL-10 levels were significantly greater in SR-BI-null mice at 24 hours, whereas the remainder showed no difference at 24 hours (data not shown). Of all the cytokines assayed, IL-4, IL-7, IL-13, and IL-15 did not show any response to LPS in either of the 2 genotypes. These are Th2 cytokines associated with allergy, autoimmune disease, and parasitic infection. Under basal conditions in the absence of LPS, no differences in cytokine levels were observed between SR-BI-null and control mice. These data clearly show that SR-BInull mice exhibit a markedly increased inflammatory response to LPS compared with control SR-BI $I^{+/+}$mice.

An overproduction of proinflammatory cytokines caused by LPS in SR-BI-null mice suggests increased susceptibility to endotoxic shock and death in these animals. Consistent with this hypothesis, we observed a marked difference in survival rate of SR-BI-null and control mice injected i.p. with a single relatively moderate dose of LPS (5 $\mu \mathrm{g} / \mathrm{g}$ body weight) (Figure 2$)$. Neither the control group 
Table 1

Cytokine levels in $S R-B \mathrm{I}^{+++}$and $S R-\mathrm{Bl}^{-/-}$mice in response to LPS

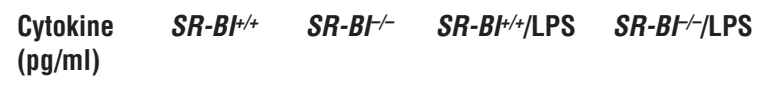

Cytokines showing differences between $S R-\mathrm{BH}^{-/}$and $S R-\mathrm{BI}^{+/+}$mice

Two hours after LPS injection

$\begin{array}{lcccc}\text { GM-CSF } & 17 \pm 14 & 13 \pm 10 & 146 \pm 22 & 332 \pm 120^{A} \\ \text { IL-1 } \beta & <3.2 & <3.2 & 17 \pm 4.5 & 47 \pm 12^{\mathrm{A}} \\ \text { IL-9 } & 12 \pm 10 & 16 \pm 13 & 28 \pm 8.0 & 47 \pm 12^{\mathrm{A}} \\ \text { IL-12 } & 40 \pm 35 & 20 \pm 10 & 80 \pm 14 & 115 \pm 5.0^{\mathrm{A}} \\ \text { MIP } & 32 \pm 31 & 30 \pm 27 & 4778 \pm 267 & 8439 \pm 270^{\mathrm{A}} \\ \text { RANTES } & 5.9 \pm 4.0 & 5.2 \pm 2.0 & 70 \pm 33 & 397 \pm 186^{\mathrm{B}} \\ \text { TNF- } \alpha & <3.2 & <3.2 & 248 \pm 50 & 864 \pm 385^{\mathrm{B}} \\ \text { Twenty-four hours after LPS injection } & & \\ \text { IL-5 } & 4.3 \pm 1.6 & 4.0 \pm 1.0 & 20 \pm 26 & 171 \pm 76^{\mathrm{B}} \\ \text { IL-6 } & 14 \pm 8.0 & 10 \pm 4.5 & 375 \pm 127 & 8432 \pm 2716^{\mathrm{B}} \\ \text { IL-10 } & <3.2 & <3.2 & 17 \pm 0.7 & 225 \pm 88^{\mathrm{B}} \\ \text { KC } & 39 \pm 11 & 28 \pm 7.6 & 183 \pm 68 & 6063 \pm 3937^{\mathrm{A}} \\ \text { MCP-1 } & 18 \pm 16 & 14 \pm 18 & 471 \pm 206 & 4744 \pm 798^{\mathrm{B}}\end{array}$

Cytokines not showing difference between $S R-B F^{-/}$and $S R-B r^{+/+}$mice

Two hours after LPS injection

$\begin{array}{lcccc}\text { IFN- } \gamma & <3.2 & <3.2 & 18.4 \pm 5.4 & 14.9 \pm 16.8 \\ \text { IL-1 } \alpha & 16 \pm 5 & 7.1 \pm 5.2 & 443 \pm 84 & 302 \pm 126 \\ \text { IL-2 } & <3.2 & <3.2 & 6.2 \pm 1.9 & 8.2 \pm 5.9 \\ \text { IL-4 } & <3.2 & <3.2 & <3.2 & <3.2 \\ \text { IL-5 } & 4.0 \pm 1.0 & 5.3 \pm 1.6 & 14.2 \pm 6.4 & 2.5 \pm 2.3 \\ \text { IL-6 } & 26 \pm 12 & 14 \pm 6 & >10000 & >10000 \\ \text { IL-7 } & <3.2 & <3.2 & <3.2 & <3.2 \\ \text { IL-10 } & <3.2 & <3.2 & 654 \pm 385 & 541 \pm 96 \\ \text { IL-13 } & 110 \pm 94 & 129 \pm 80 & 242 \pm 85 & 252 \pm 50 \\ \text { IL-15 } & 43 \pm 38 & 36 \pm 31 & 49 \pm 11 & 45 \pm 8 \\ \text { IL-17 } & 9.1 \pm 5.3 & 4.4 \pm 1.7 & 16.5 \pm 0.6 & 30 \pm 14 \\ \text { IP-10 } & 183 \pm 96 & 183 \pm 77 & 1441 \pm 435 & 1337 \pm 662\end{array}$

$S R-B l^{--}$and $S R-B l^{+++}$mice were injected i.p. with saline or $0.5 \mu \mathrm{g} / \mathrm{g}$ body

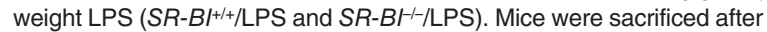
2 or 24 hours (as indicated). Serum was analyzed by cytokine protein array (multiplex biomarker assay using XMAP technology). In the case of 4 cytokines, IL-6, MCP-1, G-CSF, and keratinocyte derived chemokine $(K C)$, measured on the same array, levels were markedly induced by LPS treatment and at 2 hours exceeded $10,000 \mathrm{pg} / \mathrm{ml}$ and were not quantifiable. IL- 6 was not significantly different between the 2 groups as shown by ELISA in Figure 1. MCP-1 at 2 hours was significantly different between the 2 groups when treated with a lower dose of LPS $(0.125 \mu \mathrm{g} / \mathrm{g}$ body weight) as shown by ELISA in Figure 6 . KC was significantly greater at 24 hours in SR-BI-null mice than in control mice (Table 1A). Values shown are the mean $\pm \mathrm{SD}(n=3) .{ }^{\mathrm{A} P}<0.05 ;{ }^{\mathrm{B}} P<0.01, S R-B \mathrm{I}^{+++/ L P S}$ vs. $S R-B H^{-1 / L P S}$. Similar results were found in 2 independent experiments. IP-10, interferon-inducible protein 10.

nor the SR-BI heterozygous $(+/-)$ group had any fatalities $(n=8)$, whereas there was a $100 \%$ fatality rate within 3 days in the SR-BInull group $(n=8)$. The SR-BI-null mice showed symptoms of stress, including reduced movement, shivering, and diarrhea, whereas both the control mice and heterozygous mice appeared free of these symptoms. As was the case for mice treated with $0.5 \mu \mathrm{g} / \mathrm{g}$ body weight of LPS (Figure 1 and Table 1), SR-BI-null mice treated with the higher dose of LPS ( $5 \mu \mathrm{g} / \mathrm{g}$ body weight) showed markedly enhanced plasma levels of TNF- $\alpha$ at 2 hours compared with the control mice, whereas IL-6 levels were induced to the same extent in the 2 mouse groups at the same time point (Figure 2B).
Glucocorticoid insufficiency in SR-BI-null mice during LPS-induced inflammation. Glucocorticoids play an important regulatory role in the inflammatory response, and since SR-BI-dependent uptake of cholesterol into the adrenal is thought to be important in providing cholesterol for glucocorticoid synthesis, we evaluated adrenal function in SR-BI-null mice during LPS-induced inflammation. As demonstrated in Figure 3A, plasma corticosterone levels in control mice were markedly increased (3- to 4-fold) in response to LPS in a dose-dependent manner. Mice lacking CD36 (CD36-/-), a class B scavenger receptor closely related to SR-BI but which does not mediate efficient CE uptake from HDL (32), showed a similar corticosterone response to controls. In SR-BI-null mice, however, plasma corticosterone levels were completely unaltered during LPS-induced inflammation, indicating adrenal glucocorticoid insufficiency. A lack of corticosterone induction was also seen in SR-BI-null mice treated with the higher doses of LPS of $5 \mu \mathrm{g} / \mathrm{g}$ body weight (plasma corticosterone levels [ng/ml]: $S R-B I^{+/+}$, $124.3 \pm 25.5$ vs. $S R-B I^{+/+}$plus LPS, $1012.7 \pm 97, P<0.05$; $S R-B I^{-/-}$, $101 \pm 40$ vs. $S R-B I^{-/}$plus LPS, $\left.118 \pm 53.5, P>0.05\right)$. To determine whether this glucocorticoid insufficiency directly contributes to the increased mortality observed in SR-BI-null mice challenged with LPS, we tested the effect of corticosterone supplementation through the drinking water on survival rates in mice challenged with LPS. In the case of control mice, no deaths were observed in either the corticosterone-treated or untreated groups (Figure 3B). However, corticosterone supplementation through the drinking water markedly improved the survival rate in SR-BI-null mice, albeit not to the $100 \%$ survival rate seen in the control groups. Corticosterone supplementation significantly increased plasma corticosterone levels in SR-BI-null mice such that levels measured in surviving SR-BI-null mice and control mice were similar at 66 hours and exceeded those in unsupplemented control mice (Figure 3C). Supplementation with corticosterone also markedly reduced LPS-induced TNF- $\alpha$ levels in both SR-BI-null and control mice treated with LPS at either a low $(0.5 \mu \mathrm{g} / \mathrm{g}$ body weight) or higher dose ( $5 \mu \mathrm{g} / \mathrm{g}$ body weight), although in supplemented SR-BI-null mice at the high LPS dose, TNF- $\alpha$ levels remained at higher levels than in control mice (Figure 3D). Corticosterone did not simply delay the onset of septic shock, since the surviving mice appeared to be recovering from LPS treatment judged on the basis of the physical signs, which included improved activity, normal breathing, and lack of shivering. In addition, in surviving mice, the levels of TNF- $\alpha$ and IL- 6 were reduced to baseline or near baseline levels (less than $1 \mathrm{ng} / \mathrm{ml}$ ) at the end of the experiments.

To determine whether the lack of glucocorticoid response in SR-BInull mice is due to altered ACTH production by the pituitary or to a more direct effect at the level of the adrenal, we first compared plasma ACTH levels in both LPS-treated and control mice. ACTH levels in SR-BI-null mice and control mice were similar under basal conditions and increased significantly in response to LPS (Figure $4 \mathrm{~A})$. To investigate whether the decreased corticosterone level in the SR-BI-null mice was due to decreased responsiveness of the adrenal to ACTH stimulation, mice were injected s.c. with ACTH (Figure 4B). A maximal corticosterone level in control mice was achieved at a dose of 1 unit of ACTH, and no further increase was seen with doses up to 8 units of ACTH (data not shown). SR-BInull mice, unlike control mice, failed to respond to ACTH over a 5 -hour period following injection with 2 units of ACTH (Figure 4B) or 4 units of ACTH (data not shown). Interestingly, insufficient corticosterone production was not only found in the inflam- 

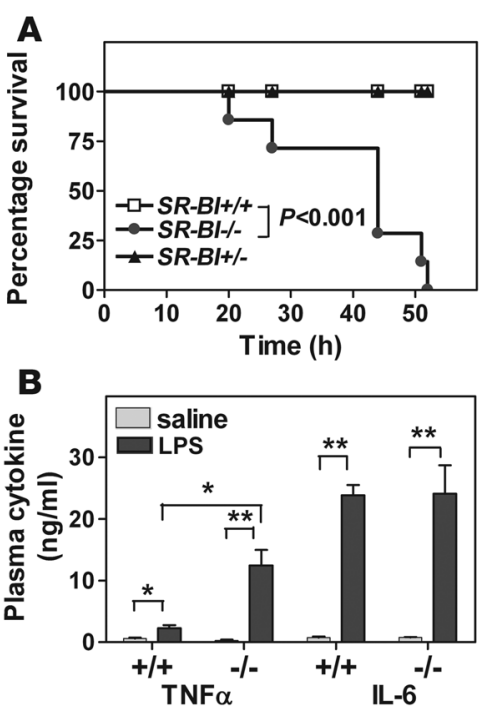

matory response but also resulted from the stress of a $5^{\circ} \mathrm{C}$ swim (Figure 4C). These experiments indicate that adrenal insufficiency occurred not only under severe acute phase response conditions but also following a common physical/mental stress challenge.

To relate our findings on the response of SR-BI-null and control mice to bacterial infection, we assessed the inflammatory response and adrenal function in SR-BI-null mice challenged with Gramnegative bacteria Escherichia coli. As shown in Figure 5, 2 hours following an E. coli challenge, plasma levels of TNF- $\alpha$ and monocyte chemoattractant protein-1 (MCP-1) were each significantly elevated in SR-BI-null mice compared with the control mice (Figure 5A). At the same time, plasma corticosterone levels were markedly lower following E. coli exposure in SR-BI-null mice than in control mice (Figure 5B). Cytokine levels and plasma corticosterone levels were similarly low in untreated SR-BI-null and control mice (data not shown). These results clearly indicate that SR-BI deficiency results in an increased inflammatory response following E. coli infection.

Adrenal insufficiency contributes to an enhanced inflammatory response and endotoxic shock in SR-BI-null mice. To further investi-

\section{Figure 2}

$S R-B I^{-1-}$ mice are more sensitive to LPS-induced lethality. (A) Survival

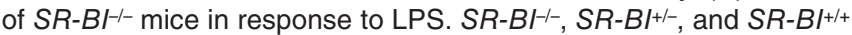
mice $(n=8)$ were injected i.p. with $5 \mu \mathrm{g} / \mathrm{g}$ body weight of LPS. Mice were carefully monitored, and survival rates at the indicated times were recorded $\left(S R-B I^{-/-}\right.$vs. $\left.S R-B I^{+++} ; P<0.001\right)$. (B) Plasma cytokine levels in $S R-\mathrm{Bl}^{-/-}$and $S R-\mathrm{Bl}^{+/+}$mice challenged with LPS. LPS $(5 \mu \mathrm{g} / \mathrm{g}$ body weight) was injected i.p. into $S R-B I^{+/+}$and $S R-B I^{-/-}$mice, and blood was collected 2 hours following LPS injection. Plasma IL- 6 and TNF- $\alpha$ levels were determined by ELISA. Values shown are the mean $\pm \mathrm{SD}(n=4)\left({ }^{\star} P<0.05 ;{ }^{* \star} P<0.01\right)$. Similar results were seen in 3 independent experiments.

gate the role of the adrenals in the LPS-induced inflammatory response, both control and SR-BI-null mice were adrenalectomized and then treated 7 days after recovery with LPS. It should be noted that adrenalectomy renders mice deficient, not only in corticosterone, but also in other adrenal hormones that may each have a role in inflammation (33). LPS was used at a relatively low dose $(0.125 \mu \mathrm{g} / \mathrm{g}$ body weight) since adrenalectomy increases sensitivity in mice to inflammation (34). Prior to LPS injection, basal levels of both TNF- $\alpha$ and MCP-1 were similarly low in control and SR-BI-null mice (data not shown). In the sham-operated SR-BInull mice, there was an inflammatory response to LPS such that the levels of TNF- $\alpha$, IL- 6 , and MCP- 1 were markedly greater than the corresponding levels in control $S R-B I^{+/+}$mice 2 hours following LPS injection (Figure 6, A-C). A greater inflammatory response to LPS was observed in the adrenalectomized mice from both groups. In the case of TNF- $\alpha$, levels were approximately $38 \%$ higher $(P<0.05)$ in the adrenalectomized SR-BI-null mice than in control mice (Figure 6A). However, no differences in either IL-6 or MCP-1 levels were observed between adrenalectomized SR-BInull and control mice under conditions in which the levels of the 2 cytokines were both extremely high (Figure 6, B and C). The differences observed in IL- 6 and MCP-1 levels between shamoperated control and SR-BI-null mice treated with LPS were not observed in the experiments shown in Figure $1 \mathrm{~B}$ and Table 1. This difference is likely related to the lower dose of LPS used in the experiment shown in Figure 6. Thus, while cytokine levels in

\section{Figure 3}

Plasma corticosterone levels are not induced in SR-B $\mathrm{I}^{--}$ mice challenged with LPS. (A) Corticosterone levels in $S R-B I^{-1-}$ and $C D 36^{-1-}$ mice injected with various amounts of LPS $(0.17,0.5$, and $1.5 \mu \mathrm{g} / \mathrm{g}$ body weight) and sacrificed 2 hours later. Values shown are the mean $\pm S D$ $(n=4)$. a, b, c, $P<0.05$. (B) $S R-B I^{-/-}$and $S R-B I^{+/+}$mice were given corticosterone $(100 \mu \mathrm{g} / \mathrm{ml}$ in $0.1 \%$ ethanol) in drinking water $\left(S R-B I^{-/ /} / \mathrm{C}, S R-B I^{+/+} / C\right)$ or $0.1 \%$ ethanol only 8 hours prior to i.p. injection of LPS $(5 \mu \mathrm{g} / \mathrm{g}$ body weight). Survival rates at the indicated times following LPS administration are shown $(n=7)$. (C) Plasma corticosterone levels in the surviving mice. Surviving mice were sacrificed 66 hours after LPS challenge. Values shown are the mean $\pm \operatorname{SD}\left(n=4\right.$ for $S R-B I^{-1-} ; n=7$ for $S R-B I^{+++}$). (D) Plasma TNF- $\alpha$ levels 2 hours after LPS injection with or without corticosterone supplementation. $S R-B I^{+/+}$and $S R-B I^{-/-}$mice were injected i.p. with 0.5 and $5 \mu \mathrm{g} / \mathrm{g}$ body weight of LPS. Values shown are the mean $\pm \mathrm{SD}(n=4) .{ }^{*} P<0.05 ;{ }^{* \star} P<0.01$. Similar results were found in 3 independent experiments.

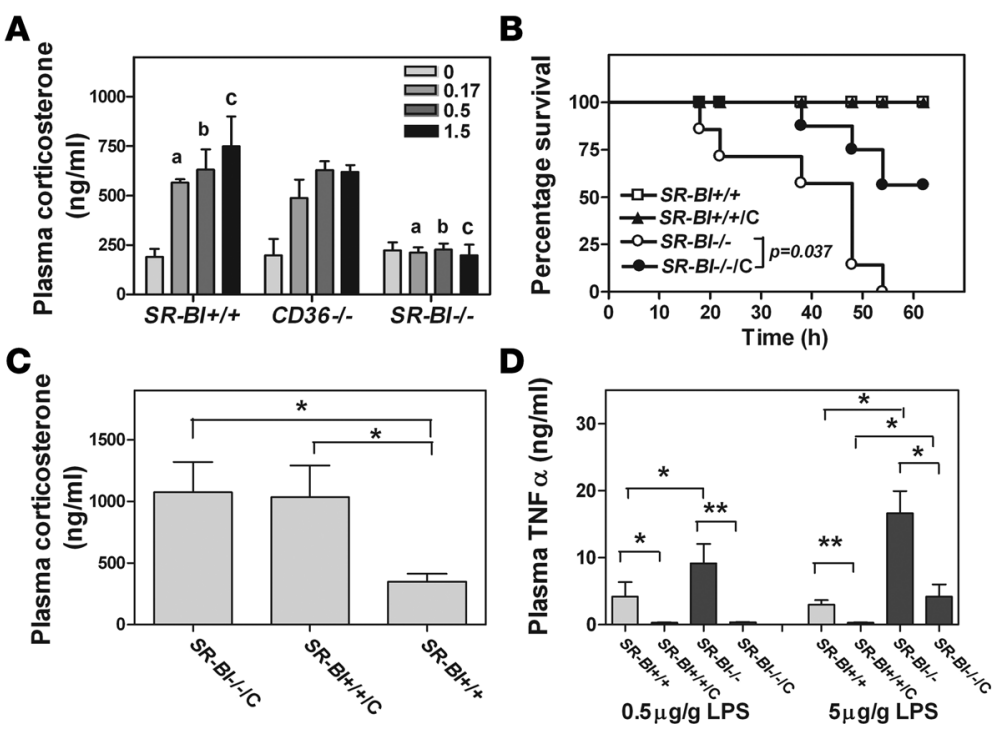



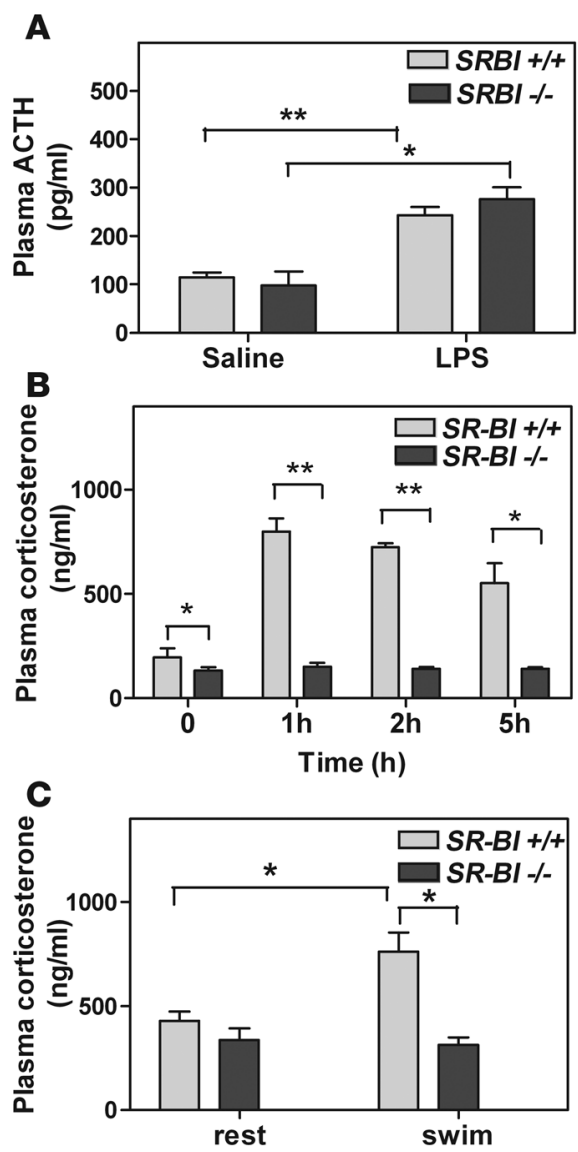

SR-BI-null mice reached similar and possibly maximal levels at the 2 LPS doses used, the responses of IL- 6 and MCP- 1 in control mice were much lower at the lower LPS dose. These results are in line with an enhanced sensitivity of SR-BI-null mice to low doses of LPS. Overall, the results of this experiment show that adrenalectomy to a large extent abolished the differences in inflammatory cytokines between SR-BI-null and control mice.

LPS-treated adrenalectomized mice of both control and SR-BInull groups showed low levels of plasma corticosterone that were similar to the levels in untreated SR-BI-null mice (Figure 6D). These data further confirm the finding that a lack of SR-BI prevents LPS-induced production of corticosterone in adrenals. In adrenalectomized mice, the levels of corticosterone were low but significant and were higher in control than in SR-BI-null mice. Extra-adrenal glucocorticoid synthesis has been reported (33), and our results point to the possibility that such extra-adrenal synthesis may also be dependent on SR-BI. Together, these data suggest that adrenal insufficiency plays a major role in contributing to the enhanced LPS-induced inflammatory response in SR-BI-null

\section{Figure 5}

Hyperinflammatory response in $S R-B I^{-1-}$ mice challenged with $E$. coli. $S R-B I^{--}$and $S R-B I^{+/+}$mice were injected i.p. with $2 \times 10^{7} \mathrm{CFU} E$. coli per mouse. Two hours after the injection, mice were sacrificed and plasma was collected. (A) Plasma cytokine levels determined by ELISA. (B) Plasma corticosterone levels determined by RIA. Values shown are mean $\pm \operatorname{SD}(n=4)$. Similar results were found in 2 independent experiments. ${ }^{*} P<0.05 ;{ }^{* \star} P<0.01$.

\section{Figure 4}

Primary adrenal deficiency in $S R-B I^{-/-}$mice. (A) Plasma ACTH levels in $S R-B I^{+++}$and $S R-B I^{-/-}$male mice challenged with LPS $(0.5 \mu \mathrm{g} / \mathrm{g}$ body weight of LPS or saline) for 2 hours (B) ACTH-induced corticosterone response in $S R-\mathrm{Bl}^{+/+}$and $S R-\mathrm{Bl}^{-/-}$mice. Male $S R-\mathrm{Bl}^{+/+}$and $S R-\mathrm{Bl}^{-{ }^{-}}$ mice were injected with $2 U$ of ACTH s.c. and sacrificed under anesthesia at the indicated times. (C) Adrenal insufficiency in $S R-B I^{--}$mice under stress. Female $S R-B I^{+/+}$and $S R-B I^{--}$mice were stressed by a 3 -minute cold water $\left(5^{\circ} \mathrm{C}\right)$ swim followed by a 17 -minute rest at room temperature. Values shown are mean \pm SD $(n=4)$. Similar results were found in 3 independent experiments. ${ }^{*} P<0.05$; ${ }^{\star \star} P<0.01$.

mice. At the same time, the significant difference between TNF- $\alpha$ levels in adrenalectomized SR-BI-null and control mice supports a conclusion that SR-BI influences inflammation by mechanisms in addition to its role on adrenal glucocorticoid production.

To address the possible mechanisms for adrenal insufficiency in SR-BI-null mice, we first examined ERK phosphorylation, a key step in the ACTH-induced signaling pathway in the adrenals (35). ERK phosphorylation to p-ERK was found to be induced by LPS within 1 hour in adrenals to a similar extent in SR-BI-null mice and control mice, with no significant changes in the levels of total ERK during the same period (data not shown). This result is consistent with ACTH signaling in the adrenals being initiated in a normal manner by ACTH in SR-BI-null mice. Two key enzymes in the biosynthesis of glucocorticoids that are transcriptionally induced during stimulation of corticosterone production from cholesterol are steroidogenic acute regulatory protein (StAR) and cytochrome P450 side-chain cleavage enzyme (Cyp11A1) (29). StAR is required for cholesterol transport across the inner mitochondrial membrane, and Cyp11A1 converts cholesterol into pregnenolone by catalyzing cholesterol side-chain cleavage. In untreated mice, the expression of both StAR and Cyp11A1 mRNA in adrenals was similar in SR-BI-null and control mice, as assessed by adrenal mRNA levels (Figure 7, A and B). Expression of mRNA for both proteins was upregulated by LPS within 1 hour in control mice and to at least the same extent in SR-BI-null mice. mRNA levels for both proteins remained higher in SR-BI-null mice compared with control mice for at least 24 hours. In line with StAR transcriptional
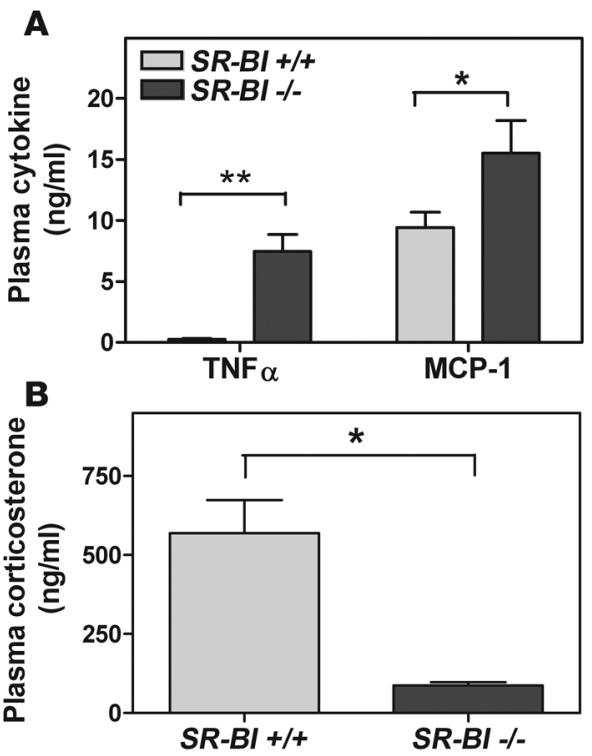
A
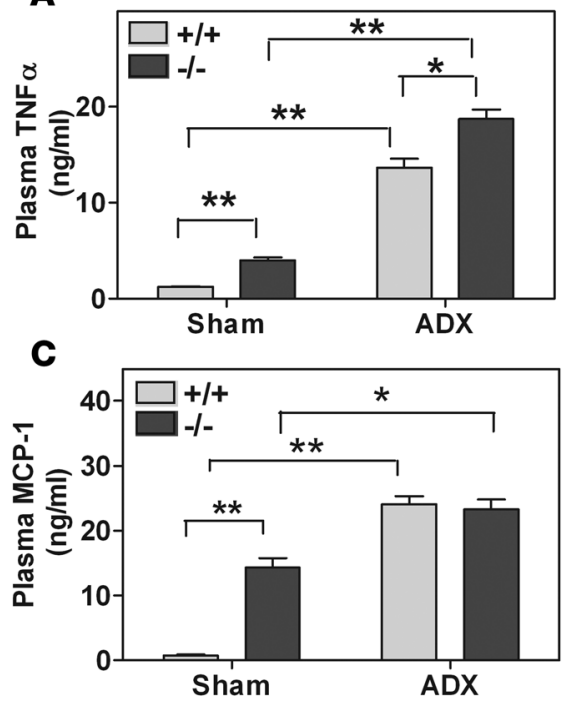

B
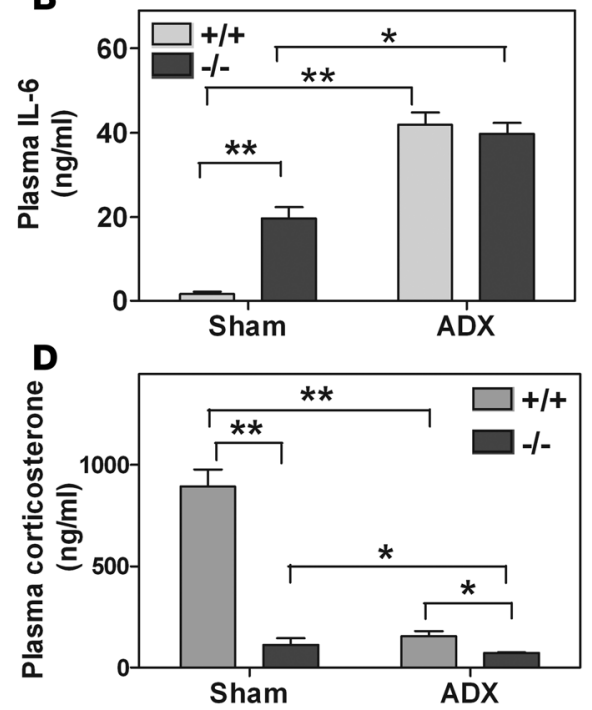

\section{Figure 6}

Effects of adrenalectomy on LPS-induced response in $S R-\mathrm{Bl}^{-/-}$and $S R-B I^{+/+}$mice. Mice were adrenalectomized and allowed to recover for 1 week. Adrenalectomized mice (ADX) and sham-operated mice (sham) were injected i.p. with LPS $(0.125 \mu \mathrm{g} / \mathrm{g}$ body weight), and 2 hours later, plasma cytokines and corticosterone levels were determined. (A) Plasma TNF- $\alpha$ levels. (B) Plasma IL-6 levels. (C) Plasma MCP-1 levels. (D) Plasma corticosterone levels. Values shown are mean \pm SD $(n=5) .{ }^{*} P<0.05 ;{ }^{* \star} P<0.01$. Similar results were found in 3 independent experiments. upregulation, the levels of StAR protein in the adrenals were also upregulated in both groups of mice and at least to the same extent in SR-BI-null mice as in control mice (Figure 7C). These results again suggest normal adrenal regulatory responses in respect to ACTH signaling in SR-BI-null mice.

The availability of unesterified cellular cholesterol is a key determinant in corticosterone production (29). To assess whether the inability of SR-BI-null mice to induce corticosterone synthesis in SR-BI-null mice results from limited cholesterol availability in the adrenal, we analyzed the expression of 2 proteins, the LDLR and HMG-CoA reductase, whose expression at the transcriptional level is highly regulated by the level of intracellular cholesterol $(25,36)$. The LDLR serves to internalize LDL, and HMG-CoA reductase is the key regulatory enzyme in cholesterol biosynthesis.
Adrenal mRNA levels for the 2 proteins were determined in control and SR-BI-null mice before and after LPS treatment (Figure 7, D and E). Basal LDLR mRNA levels were about 2-fold greater in SR-BI-null than in control mice, indicative of decreased cellular cholesterol levels in SR-BI-null mice, as previously reported by others (31) (Figure 7D). In the case of control mice, mRNA levels for LDLR were moderately increased ( $<2$ fold) following LPS treatment and returned to unstimulated levels within 24 hours. In contrast, LPS induced a striking increase in LDLR mRNA levels in SR-BI-null mice to levels that were about 4- to 5-fold higher than those in control mice. Similarly, HMG-CoA reductase was markedly upregulated (about 7-fold) in SR-BI-null mice but was relatively unchanged in control mice following LPS treatment (Figure 7E). The extensive transcriptional upregulation of these

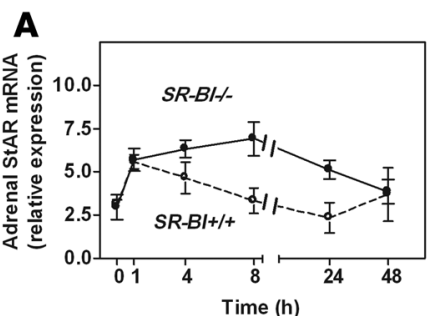

C

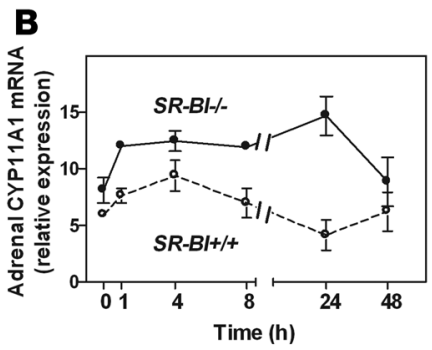

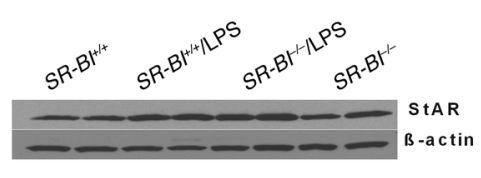
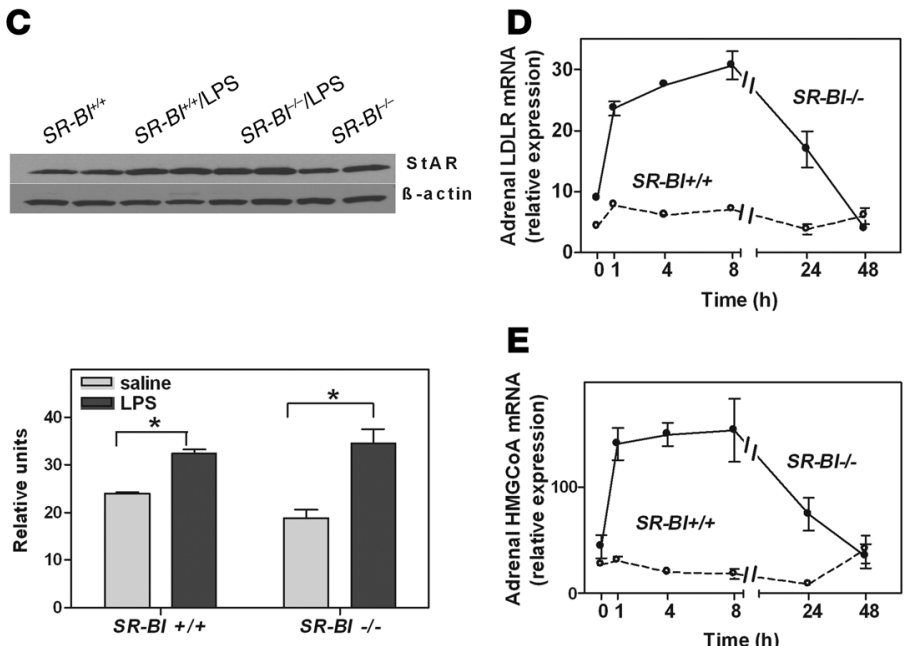

E

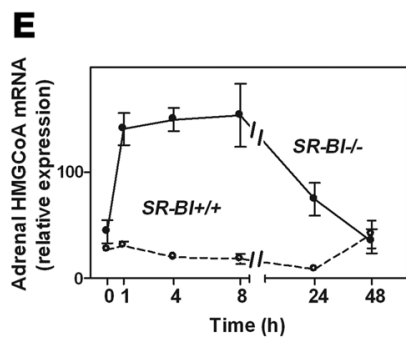

Figure 7

Adrenal gene expression during LPS-induced inflammatory response. $S R-B I^{+/+}$and $S R-B I^{-/-}$mice were injected i.p. with $0.5 \mu \mathrm{g} / \mathrm{g}$ body weight of LPS. Mice were sacrificed at indicated time points, and adrenals were collected for mRNA extraction and Q-PCR. (A) Adrenal StAR mRNA. (B) Adrenal Cyp11A1 mRNA. (C) Adrenal StAR Western blot (10 $\mu \mathrm{g}$ cell protein/lane). Mice were sacrificed 2 hours after LPS injection. Adrenals were collected, and proteins were extracted. (D) Adrenal LDLR mRNA. (E) Adrenal HMG-CoA reductase mRNA. Values shown are mean \pm SD $(n=3)$ of the ratio of genes for the target genes to that of the 18S rRNA. Similar results were found in 2 independent experiments. 


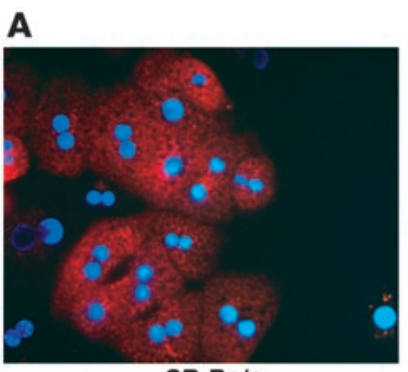

$S R-B+/+$

B

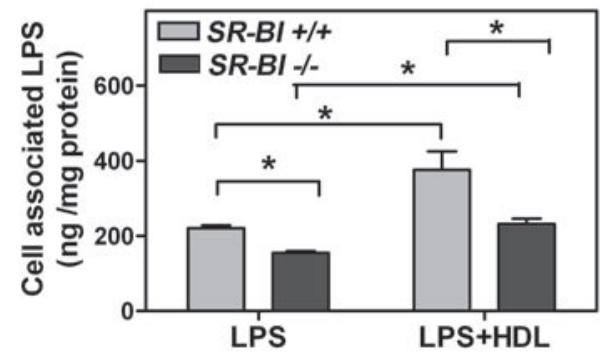

2 proteins by LPS in SR-BI-null mice indicates that, following LPS treatment, there is a rapid and marked decrease in cellular unesterified cholesterol, presumably due to an inability of cells to replenish intracellular cholesterol from circulating lipoproteins, intracellular biosynthesis, or cellular CE stores. Recent studies suggest that the cholesterol transporter ABCA1 may also contribute to adrenal cholesterol regulation (37). We evaluated adrenal ABCA1 expression in mice in response to LPS and found that both ABCA1 mRNA and protein levels were significantly lower in SR-BInull mice, suggesting that ABCA1 did not contribute to low cellular cholesterol levels in these mice (data not shown).

We conclude from these results that SR-BI in the adrenals is required to provide, through the process of selective CE uptake, sufficient cholesterol for glucocorticoid production under conditions of high adrenal stimulation by ACTH, such as occurs during LPS-induced inflammation.

SR-BI plays a role in LPS clearance into hepatocytes. Since LPS is cleared largely via hepatocytes (8), which express high levels of SR-BI, and since SR-BI functions as a receptor for both HDL and LPS, we investigated whether SR-BI is responsible for LPS clearance by the liver. Cultured primary hepatocytes were isolated from control and SR-BI-null mice and assayed for their ability to take up LPS. As shown in Figure 8A, fluorescently labeled Alexa Fluor-LPS was taken up rapidly within 1 hour into control hepatocytes but to a significantly lesser extent in SR-BI-null hepatocytes. Similarly, cell association of ${ }^{125}$ I-LPS was decreased in SR-BI-null hepatocytes

\section{Figure 9}

LPS distribution in the liver. (A) LPS distribution in hepatocytes and nonhepatocytes. ${ }^{125} \mathrm{I}-\mathrm{LPS}(0.125 \mu \mathrm{g} / \mathrm{g}$ body weight) was injected through the tail vein into $S R-B I^{-/-}$and $S R-B I^{+/+}$mice. After 2 hours, mice were sacrificed and hepatocytes and nonhepatocytes were isolated. (B) LPS tissue distribution. ${ }^{125}$ I-LPS $(0.125 \mu \mathrm{g} / \mathrm{g}$ body weight) was injected through the tail vein into $S R-\mathrm{Bl}^{-/-}$and $S R-\mathrm{Bl}^{+++}$mice. Plasma, liver, kidney, and spleen were collected after 30 minutes. LPS distribution was calculated as percentage of the total injected LPS dose. Values shown are the mean $\pm \operatorname{SD}(n=4) .{ }^{*} P<0.05$. Similar results were found in 3 independent experiments.

\section{Figure 8}

SR-BI-dependent uptake of LPS in hepatocytes. (A) Primary hepatocytes were washed and incubated with $5 \mu \mathrm{g} / \mathrm{ml}$ of Alexa Fluor-LPS at $37^{\circ} \mathrm{C}$ for 1 hour in DMEM medium containing $0.5 \%$ BSA. Fluorescence microscopy was performed at $\times 40$ original magnification with equal exposures (Alexa Fluor-LPS, red; DAPI, blue, nuclear stain). (B) Association of lipid-free and HDL-bound ${ }^{125}$ I-LPS with $S R-B I^{+/+}$and $S R-\mathrm{Bl}^{-/-}$primary hepatocytes. Where indicated (LPS + $\mathrm{HDL}),{ }^{125}$-LPS $(5 \mu \mathrm{g})$ was preincubated with human $\mathrm{HDL}_{3}(10 \mu \mathrm{g})$ at room temperature for 30 minutes before addition to cells. Hepatocytes were incubated with $5 \mu \mathrm{g} / \mathrm{ml} 125$ I-LPS or $125 \mid$-LPS $+\mathrm{HDL}$ at $37^{\circ} \mathrm{C}$ for 1 hour in DMEM medium containing $0.5 \%$ BSA. Values shown are the mean \pm SD of triplicate determinations $\left({ }^{*} P<0.05\right)$. Similar results were found in 4 independent experiments.

(Figure 8B). Interestingly, SR-BI can mediate ${ }^{125}$ I-LPS uptake more efficiently when LPS is in its HDL-associated form. While the uptake of LPS is reduced in SR-BI-null hepatocytes, a significant level of SR-BI-independent uptake was observed, suggesting the involvement of other candidate receptors, such as SR-A, in this process. The clearance of ${ }^{125}$ I-LPS from plasma and its uptake into the liver was also investigated in control and SR-BI-null mice. First, the uptake of ${ }^{125}$ I-LPS into hepatocytes and nonhepatocytes isolated from livers collected 2 hours after LPS injection was measured. In line with the uptake of Alexa Fluor-LPS in cultured hepatocytes (Figure 8A), uptake of ${ }^{125}$ I-LPS was significantly lower (by approximately $50 \%$ ) in the hepatocytes, but not nonhepatocytes, of SR-BI-null mice compared with control mice (Figure 9A). Thirty minutes following injection, ${ }^{125}$ I-LPS uptake into the liver of SR-BI-null mice was significantly lower (by approximately 40\%) than in control mice (Figure 9B). In contrast, uptake of ${ }^{125}$ I-LPS into the spleen and kidney was similar in the 2 animal groups (Figure $9 \mathrm{~B})$. In line with the reduced uptake of ${ }^{125}$ I-LPS into the liver of SR-BI-null mice, ${ }^{125}$ I-LPS remaining in plasma was greater in SR-BI-null mice. We conclude from these results that hepatic SR-BI expressed in hepatocytes plays a major physiologically significant role in clearance of LPS from plasma.

To assess whether the observed differences between control and SR-BI-null mice in response to LPS might be related to previously
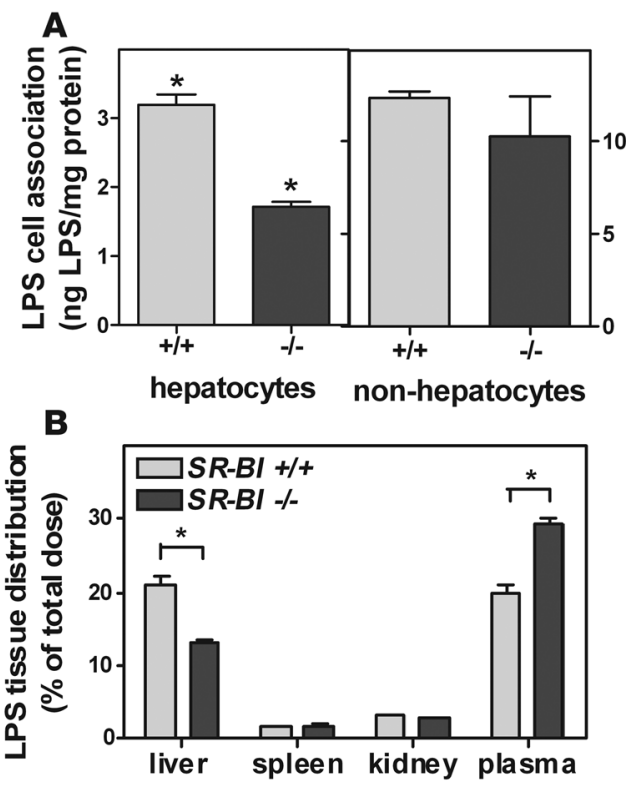




Figure 10

Plasma from $S R-B I^{+++}$and $S R-B I^{-/-}$mice showed similar LPS neutralization activity. Plasma (1 $\mu \mathrm{l}$ ) from $S R-B \mathrm{I}^{+/+}$and $S R-B I^{-/-}$mice (pooled from 4 mice in each group) was incubated with different amounts of LPS (10 ng, $25 \mathrm{ng}, 50 \mathrm{ng}$, and $100 \mathrm{ng}$ ) at $37^{\circ} \mathrm{C}$ for 1 hour. Endotoxin activities relative to no-plasma controls at each LPS concentration (percentage of neutralization) were determined by using a commercially available LAL assay kit. Similar results were found in 3 independent experiments.

described differences in HDL levels or HDL structure or composition in the 2 mouse strains, we analyzed plasma lipoprotein profiles in mice before and after LPS treatment. As previously reported, plasma HDL cholesterol levels were elevated more than 2-fold in SR-BI-null mice compared with control mice (38), and the HDL particles in SR-BI-null mice were abnormally large and contained a higher content of free cholesterol (31) (data not shown). An LPS challenge lowered HDL cholesterol levels in both SR-BI-null mice and the control mice: $S R-B I^{-/-}$basal, $220.6 \pm 4.8 \mu \mathrm{g} / \mathrm{dl}$, vs. $S R-B I^{-/-}$ plus LPS, $158.5 \pm 14.5 \mu \mathrm{g} / \mathrm{dl}(P<0.05) ; S R-B I^{+/+}$basal, $79.1 \pm 8.3 \mu \mathrm{g} / \mathrm{dl}$, vs. $S R-B I^{+/+}$plus LPS, $57.3 \pm 8.1 \mathrm{mg} / \mathrm{dl}(P<0.05)$. Free cholesterol was also decreased to a similar extent between the 2 mouse strains: $S R-B I^{-1-}$ basal, $86.9 \pm 4.36 \mu \mathrm{g} / \mathrm{dl}$, vs. $S R-B I^{-/-}$plus LPS, $69.2 \pm 3.92 \mu \mathrm{g} / \mathrm{dl}$ $(P<0.05)$; $S R-B I^{+/+}$basal, $24.5 \pm 1.89 \mu \mathrm{g} / \mathrm{dl}$, vs. $S R-B I^{+/+}$plus LPS, $17.9 \pm 0.57 \mu \mathrm{g} / \mathrm{dl}(P<0.05)$. A Limulus amebocyte lysate (LAL) assay was used to measure the neutralizing effect of lipoprotein from SR-BI-null mice and control mice. No difference in plasma LPS neutralization was found between the 2 genotypes (Figure 10). This indicates that HDL from SR-BI-null mice, like control mice, is able to bind and neutralize LPS effectively.

\section{Discussion}

The present study demonstrates that SR-BI-null mice exhibit an enhanced inflammatory response to LPS as shown by highly elevated levels of inflammatory cytokines compared with control mice and decreased survival when challenged with endotoxin. This occurs despite the elevated levels of HDL in these mice, which is normally protective against LPS-induced inflammation. Strikingly, SR-BI-null mice failed to show any significant induction of corticosterone production in response to LPS. A lack of glucocorticoid stimulation was also observed in these mice in response to exogenous ACTH, indicating that the glucocorticoid insufficiency is not due to impaired signaling in the hypothalamic-pituitaryadrenal axis upstream of the adrenals but rather is the result of primary adrenal deficiency due to an inadequate cholesterol supply. In addition to its role in glucocorticoid production, our results show that SR-BI also plays a role in the clearance of plasma LPS.

Our findings that corticosterone supplementation in SR-BI-null mice exerts a major protective effect against endotoxin-induced death provides strong support for a key protective role for glucocorticoids in endotoxin-induced death. Glucocorticoids act to efficiently limit the inflammatory response (39), and stimulation of glucocorticoid production by the adrenals has generally been considered a key component in host defense against severe inflammation and endotoxic shock (27). Our results further point to the strong possibility that SR-BI protects against endotoxemia in part through its role in glucocorticoid biosynthesis. However, since pharmacological doses of glucocorticoids have been shown to be protective even in the absence of adrenal insufficiency (28), it is possible that glucocorticoid supplementation at the relatively high levels reached in the SR-BI-null mice protects against endotoxemia in a manner unrelated to the adrenal insufficiency present in these mice. Since endotoxic shock is often associated with low levels of glucocorticoids, glucocorticoids have long been used in the management of sepsis and shown to efficiently limit uncontrollable inflammation (1). However, the concept of adrenal deficiency during sepsis is complex and is still in some doubt (28). Clinical trials, for example, have not shown survival benefit with the early use of high-dose corticosteroids in adrenally intact patients with severe sepsis (1). On the other hand, survival benefit was seen in a group of adrenally insufficient patients that did not respond to a corticotropin-stimulation test (28), and further clinical studies on the role of glucocorticoids in sepsis are therefore required.

During the acute phase of inflammatory response, the increased secretion of corticosterone depends on increased synthesis, a complex process involving a number of key regulatory steps. Our results show a normal increase in ACTH levels in SR-BI-null mice in response to LPS as well as a typical adrenal response to ACTH. Thus, LPS induced plasma levels of ACTH similar to those in control mice and also triggered typical ERK phosphorylation in the adrenals. Two other key regulatory proteins were shown to respond to stimulation of SR-BI-null mice similarly to control mice. StAR, which is required for cholesterol transport to the inner leaflet of mitochondria (29), and Cyp11A1, the side-chain cleavage enzyme responsible for pregnenolone formation (29), are both upregulated in adrenals in SR-BInull mice as in control mice. Together, our data indicate normal ACTH release and consequent signaling in the adrenals in response to LPS and point to insufficient uptake of cholesterol required for glucocorticoid synthesis in SR-BI-null mice.

Corticosterone synthesis is dependent on an adequate supply of cholesterol to the adrenal cortex zona fasciculata cells. Cholesterol for steroid synthesis is derived largely from plasma lipoproteins in animals as well as humans $(25,40)$. Previous studies have shown that cholesterol can be taken up from HDL by SR-BI in the form of esterified and free cholesterol, although CEs likely contribute to the majority of uptake $(20,41,42)$. Cholesterol is also taken up from LDL by both the $\operatorname{LDLR}(23)$ and SR-BI $(22,43)$. However, HDL appears to be the more important source of cholesterol $(24,30)$. Consequently, apoA-I-null mice with low plasma HDL fail to accumulate $\mathrm{CE}$ in the adrenals and were shown to have a reduced glucocorticoid response to a swim stress test or ACTH challenge (30). Although SR-BI-null mice were found to have no gross phenotypic alterations, it was not clear whether these animals had an altered steroidogenic response (10). Our results show that during severe stress such as occurs in the response to LPS, SR-BI is absolutely required for enhanced corticosterone synthesis. Moreover, in addition to its role in the response to bacterial LPS, SR-BI was shown to be required for a normal glucocorticoid response to the conditions of a swim stress test. Thus, the critical role of SR-BI is not limited 
Table 2

Q-PCR primer sequences

\begin{tabular}{|c|c|c|c|}
\hline Gene & $\begin{array}{l}\text { Accession } \\
\text { number }\end{array}$ & Primers & $\begin{array}{l}\text { NT location } \\
(\text { size, bp })^{A}\end{array}$ \\
\hline LDLR & Z-19521 & $\begin{array}{l}\text { 5'-AGGCTGTGGGCTCCATAGG-3' } \\
\text { 5'-TGCGGTCCAGGGTCATCT-3' }\end{array}$ & $\begin{array}{l}1181-1252 \\
\quad(72)\end{array}$ \\
\hline $\begin{array}{l}\text { HMG-CoA } \\
\text { reductase }\end{array}$ & NM_008255 & $\begin{array}{l}\text { 5'-CTTGTGGAATGCCTTGTGATTG-3' } \\
\text { 5'-AGCCGAAGCAGCACATGAT-3' }\end{array}$ & $\begin{array}{c}578-653 \\
(76)\end{array}$ \\
\hline TNF- $\alpha$ & NM_013693 & $\begin{array}{c}\text { 5'-GGCAGGTCTACTTTGGAGTCATTG-3' } \\
\text { 5'-GTTAGAAGGATACAGACTGG-3' }\end{array}$ & $\begin{array}{l}833-970 \\
(138)\end{array}$ \\
\hline IL-6 & NM_031168 & $\begin{array}{c}\text { 5'-CAACGATGATGCACTTGCAG-3' } \\
\text { 5'-GTAGCTATGGTACTCCAGAAG-3' }\end{array}$ & $\begin{array}{l}265-400 \\
(136)\end{array}$ \\
\hline StAR & NM_011485 & $\begin{array}{l}\text { 5'-TTGGGCATACTCAACAACCA-3' } \\
\text { 5'-GAAACACCTTGCCCACATCT-3' }\end{array}$ & $\begin{array}{c}312-414 \\
(103)\end{array}$ \\
\hline CYP11A1 & NM_019779 & $\begin{array}{l}\text { 5'-CGAGACTTCAGCCAGTACCC-3' } \\
\text { 5'-GCCAGCATCTCGGTAATGTT-3' }\end{array}$ & $\begin{array}{l}906-1003 \\
(98)\end{array}$ \\
\hline ABCA1 & NM_013454 & $\begin{array}{c}\text { 5'-AGCCAGAAGGGAGTGTCAGA-3' } \\
\text { 5'-CATGCCATCTCGGTAAACCT-3' }\end{array}$ & $\begin{array}{l}2955-3056 \\
(102)\end{array}$ \\
\hline
\end{tabular}

ANumbers without parentheses refer to primer location on the gene, while numbers within parentheses refer to PCR product size.

to the response of the foreign inflammatory agent LPS but is also important in the glucocorticoid response to physical and mental stress unrelated to bacterial infection.

The cholesterol supply in adrenals is potentially derived from 3 main sources, namely (a) CE from circulating HDL or LDL, (b) CE from CE droplets present in cells, and (c) endogenous cholesterol synthesis. While cholesterol synthesis may provide sufficient cholesterol for basal corticosterone synthesis, our results in SR-BI-null mice show that, under conditions of high demand, endogenous synthesis is unable to support increased corticosterone production. This occurs despite a marked induction of HMG-CoA reductase, the key regulatory enzyme in cholesterol biosynthesis. Similarly, despite its marked upregulation, the LDLR was also unable to support enhanced corticosterone production in these mice. This is in line with earlier findings that corticosterone production in LDLRnull mice is unimpaired (25). Our results clearly demonstrate that SR-BI-mediated selective CE uptake is essential for enhanced corticosterone production. The CE taken up by SR-BI serves as a source of cholesterol in CE droplets found in adrenocortical cells, as previously shown by the reduced cellular CE content in apoA-I-null and also SR-BI-null mice $(10,30)$. Such droplets are considered to be short-term stores of cholesterol for glucocorticoid synthesis, since they are rapidly depleted under ACTH stimulation (40). CE taken up by SR-BI may also be used more directly for glucocorticoid synthesis following its uptake and rapid hydrolysis by hormone-sensitive lipase (41). Hormone-sensitive lipase plays a key role in the hydrolysis of CE delivered to cells by SR-BI as well as CE stored in CE droplets (25). Although the SR-BI-null mice used in this study lack both SR-BI and SR-BII isoforms, SR-BI likely contributes to the vast majority of CE uptake, since SR-BII is expressed at low levels in the adrenals compared with SR-BI and is also less active in cholesterol uptake than SR-BI (17).

The critical role of SR-BI in glucocorticoid production suggests that downregulation of SR-BI-mediated HDL cholesterol delivery to the adrenals may be a mechanism contributing to glucocorticoid insufficiency, which is often observed during sepsis. During the inflammatory response to endotoxin, SR-BI has been shown to be downregulated in hepatocytes (44) and macrophages (45).
Although the effect of LPS on SR-BI regulation in the adrenals is not known, downregulation of SR-BI would reduce cholesterol supply to the adrenal and may lead to decreased glucocorticoid production. Furthermore, the inflammatory response is typically characterized by a relatively rapid reduction in plasma levels of HDL cholesterol and apoA-I (46). Although the mechanisms responsible for this rapid decline in HDL remain uncertain, reduced HDL levels would also be expected to decrease SR-BI-mediated HDL cholesterol delivery to the adrenals. The combined effects of reduced HDL and SR-BI during inflammation may thus lead to significant reductions in glucocorticoid production.

Our finding that corticosterone supplementation did not completely normalize endotoxin-induced death in SR-BI-null mice, together with the fact that adrenalectomy did not completely abolish the difference in TNF- $\alpha$ response between SR-BI-null and control mice, indicates that SR-BI exerts other nonadrenal protective functions. SR-BI-null mice have abnormally large cholesterol-rich HDL particles due to defective HDL CE clearance (31). The apoA-I levels in normal and SR-BI-null mice are similar, suggesting that the number of HDL particles in the 2 mouse strains are also similar. Since lipoproteins such as LDL (5) and HDL (47) have strongly protective effects through their ability to neutralize LPS, we investigated whether an enhanced susceptibility of SR-BI-null mice to LPS might be due to an inability of the abnormal HDL in these mice to neutralize LPS. Our results, however, showed that the total LPS neutralizing activity of plasma from SR-BI-null and control mice was similar, thus showing effective binding and neutralization in both cases.

Earlier studies have shown that LPS, either in lipid-free form or when associated with HDL, is bound and internalized by SR-BI in HeLa cells and macrophages (15). On this basis, SR-BI might facilitate LPS clearance into hepatocytes, thereby decreasing the LPS burden. Our findings demonstrate that SR-BI indeed contributes significantly to LPS uptake into hepatocytes and to LPS clearance into the liver. In the case of nonhepatocytes, no significant difference was found in LPS association between control cells and SR-BInull cells. Although earlier studies have pointed to the ability of Kupffer cells to take up and detoxify LPS, the mechanisms for this are ill-defined (8). However, our results suggest that the stimulation of inflammatory cytokines by LPS in Kupffer cells does not depend on the ability of SR-BI to bind or internalize LPS, as has been reported in the case of the THP-1, a human monocyte cell line (48). Thus, while SR-BI may serve other protective and antiinflammatory functions, these occur within the context of a powerful glucocorticoid response to LPS and proper clearance of LPS through the hepatocytes.

Sepsis is a complex process that can be divided into an early hyperinflammatory response stage that induces acute organ dysfunction and a later hypoinflammatory stage associated with immunosuppression (1). Treatment of sepsis is complicated, given the opposing natures of these 2 stages. Our findings suggest that SR-BI exerts protective functions throughout the process of sepsis, first by allowing a normal glucocorticoid response in the early hyperinflammatory stage and second, by limiting the LPS 
burden during both stages by promoting LPS clearance. A recent study has reported that SR-BI protects against endotoxin-induced death by preventing NO-induced cytotoxicity (19). NO generation is induced during septic shock and contributes significantly to the symptoms of septic shock. Our results suggest that the glucocorticoid insufficiency seen in SR-BI-null mice might lead to enhanced endotoxic shock since glucocorticoids are known to inhibit NO production in a wide variety of cells (49). In the study by Li et al., however, NO levels in SR-BI-null mice were shown to be only moderately increased by LPS compared with control mice and the authors concluded that SR-BI prevents NO-induced cytotoxicity by mechanisms unrelated to NO synthesis (19).

Our data raise the possibility that the known protective role of SR-BI against atherosclerosis may be related to its antiinflammatory function. SR-BI-null mice and combined SR-BI/LDLR double-knockout mice on high-fat diets show accelerated atherosclerotic lesion development compared with control mice (50, 51). SR-BI/apoE-double-knockout mice not only develop atherosclerotic plaques but also have severe cardiac malfunction that includes spontaneous myocardial infarction and cardiac failure (52). Clearly, the lack of proper hepatic HDL cholesterol clearance will have significant effects in these SR-BI-null models. Nevertheless, our findings suggest that an enhanced inflammatory response may also contribute to atherogenesis in SR-BI-null mice. In SR-BI-null mice, for example, we show that chemokines produced in macrophages and vascular cells, such as MCP-1 and RANTES, are markedly upregulated during inflammation. These chemokines have been reported to promote the initiation of plaque formation $(53,54)$. Studies using these models will need to take cognizance of possible effects of altered adrenal function. Furthermore, SR-BI may also play important roles in the clearance of endogenous proinflammatory reagents, including modified lipoproteins, such as oxidized LDL and other proinflammatory lipids, and pathogens. In contrast, mice lacking the class B scavenger receptor CD36, which reportedly can also clear LPS in vitro (18), did not show the exaggerated inflammatory response to LPS seen in SR-BI-null mice. In fact, although CD36-null macrophages showed a reduced cytokine response to LPS and E. coli challenge, CD36 deficiency in mice did not protect them from E. coli-induced lethality (55).

In summary, we demonstrate that SR-BI-mediated cholesterol delivery to the adrenals is essential for an effective antiinflammatory glucocorticoid response to LPS or stress and SR-BI regulates LPS-induced inflammation and endotoxic shock. SR-BI serves a protective function in mediating LPS clearance from the plasma.

\section{Methods}

Animals and reagents. SR-BI-deficient mice (SR-BI null) were obtained from M. Krieger (Massachusetts Institute of Technology, Cambridge, Massachusetts, USA) (31). These mice lack both functional SR-BI and SR-BII. SR-BI homozygous ( $\left.S R-\mathrm{BI}^{-/-}\right)$mutant mice and control mice (both 1:1 mixed C57BL/ $6 \times 129$ backgrounds) were bred from 2 lines generated from a common mating pair of SR-BI heterozygous $\left(S R-B I^{-/+}\right)$mice. Since female $S R-B I^{-/-}$mice are infertile, $S R-B I^{-/-}$mice were bred using $S R-B I^{-/-}$male and $S R-B I^{-/+}$female mice. For all animal experiments, 8- to 12 -week-old male and female mice, weighing 20-25 g, were used. All animal experiments were approved by the Veterans Affairs Medical Center, Institutional Animal Care and Use Committee.

LPS (E. coli serotype 0111:B4; $1 \times 10^{6}$ endotoxin units/mg LPS) was obtained from Sigma-Aldrich. Corticosterone and ACTH ${ }^{125}$-I RIA assay kits were obtained from MP Biomedical. TNF- $\alpha$ and IL-6 ELISA kits were from R\&D Systems, MCP-1 ELISA set was from BD Diagnostics, and the LAL assay kit was obtained from Cape Cod Inc.

E. coli (ATCC25922; ATCC) were cultured in Luria-Bertani broth and tryptic soy broth (ATCC) at $37^{\circ} \mathrm{C}$ using standard procedures and harvested at mid-log phase, which reached $\mathrm{OD}_{660}=5.0\left(\sim 2 \times 10^{8} \mathrm{CFUs} / \mathrm{ml}\right)$. Bacteria were washed twice, suspended in sterile saline, and injected i.p. into mice $\left(2 \times 10^{7}\right.$ CFUs E. coli $100 \mu \mathrm{l}$ saline $)$.

Corticosterone and ACTH determination. Plasma was isolated from blood obtained from SR-BI-null or control mice. Samples were assayed immediately to avoid degradation. Corticosterone levels and ACTH in the plasma were determined using specific radioimmunoassay kits ( ${ }^{125}$ I-RIA kit for ACTH and corticosterone; MP Biomedicals).

Cytokine determination. Serum was isolated from the blood of SR-BInull and control mice and immediately frozen at $-80^{\circ} \mathrm{C}$. Cytokine levels were determined by multiplex biomarker assay using xMAP technology by Linco Diagnostic Services Inc. Cytokine values were calculated using standard concentration curves determined for each cytokine on each 96well plate used. Plasma TNF- $\alpha$ levels and IL- 6 levels were also determined using ELISA kits from R\&D systems; MCP-1 was determined using ELISA sets from BD Diagnostics.

Q-PCR. Total RNA was isolated from mouse liver and adrenals using the standard TRIzOL method (Invitrogen). RNA was further purified with DNase I (Roche) and RNeasy Mini Kit (QIAGEN). $2 \mu \mathrm{g}$ of RNA was reverse transcribed into cDNA using a reverse-transcription system (Promega). After 4-fold dilution, $5 \mu \mathrm{l}$ was used as a template for Q-PCR. Primers used in this study are listed in Table 2. Amplification was done for 40 cycles using Power SYBR Green PCR master Mix Kit (Applied Biosystem) and DNA Engine Optical 2 System (MJ Research Inc.). Both internal control (18S rRNA) and negative control (minus reverse transcriptase) were included. Values of each RNA sample were the average of duplicate assays normalized toward 18S rRNA (internal control) levels.

${ }^{125}$ I radioiodination and Alexa Fluor labeling of LPS. LPS was iodinated by the chloramine T method (56). In brief, $1 \mathrm{mg}$ of LPS was dissolved in $0.05 \mathrm{M}$ borate buffer $(\mathrm{pH}=8)$ and incubated with $50 \mathrm{mM}$ pOH methylbenzimidate at $37^{\circ} \mathrm{C}$ for 18 hours. After extensive dialysis, the M-LPS was radiolabeled with $\mathrm{Na}^{125}$ I by the chloramine $\mathrm{T}$ method. After iodination, the unincorporated $\mathrm{Na}^{125}$ I was removed by extensive dialysis against sterile saline at $4^{\circ} \mathrm{C}$. For fluorescent labeling of LPS, $1 \mathrm{mg}$ of LPS was incubated with 1 vial of Alexa Fluor 488 dye (Invitrogen) in $0.1 \mathrm{M}$ sodium borate buffer $(\mathrm{pH}=10.5)$ for 3 hours at $37^{\circ} \mathrm{C}$. After incubation, the mixture was dialyzed exhaustively against 4 liters of $150 \mathrm{mM} \mathrm{NaCl}$ with at least 6 changes. The bioactivity of labeled LPS was determined by the LAL assay kit. Near-identical bioactivity was observed among unlabeled LPS, 125-I-LPS, and Alexa Fluor-LPS.

LPS neutralization assay. Lipoproteins were preincubated with various amounts of LPS at $37^{\circ} \mathrm{C}$ for 1 hour, after which LAL activity of LPS was quantitatively determined according to the manufacturer's instructions. The analytical sensitivity of the kit is $0.005 \mathrm{EU} / \mathrm{ml}(0.5 \mathrm{pg}$ of highly purified LPS/ml).

Primary hepatocyte isolation and culture. The isolation of primary hepatocytes and nonhepatocytes was performed as described earlier (57) with certain modifications. In brief, livers were minced and dissociated in collagenase containing medium at $37^{\circ} \mathrm{C}$ for $10-12$ minutes. Cell suspensions were filtered through mesh $(100 \mu \mathrm{m})$ and spun down. Hepatocytes were collected after a first spin ( $50 \mathrm{~g}$ for 2 minutes), while the nonhepatocytes were collected after a second spin (500 $\mathrm{g}$ for 10 minutes). Hepatocytes were washed twice in HBSS and suspended in enriched Williams' E Medium (GIBCO; Invitrogen). Viable cells were counted and plated in 24-well mouse collagen IV-coated plates (Fisher). 
LPS uptake into primary hepatocytes. Cell association assays were performed as described previously (13). In brief, primary hepatocytes were seeded into 24-well cell culture clusters at an initial density of $1 \times 10^{5} \mathrm{cells} / \mathrm{cm}^{2}$. When cells reached confluency, they were washed with phosphate-buffered saline and incubated at $37^{\circ} \mathrm{C}$ for 2 hours with ${ }^{125}$ I-LPS in DMEM medium containing $0.5 \%$ essentially fatty acid free albumin (BSA). After incubation, medium was removed and the cells were washed 4 times with cold buffer (50 mM Tris- $\mathrm{HCl}, 150 \mathrm{mM} \mathrm{NaCl}, \mathrm{pH} 7.4)$ containing BSA $(2 \mathrm{mg} / \mathrm{ml})$ followed by 2 washes in the same buffer without BSA. The cells were then solubilized in $0.1 \mathrm{~N} \mathrm{NaOH}$ for 1 hour at room temperature, and the protein and ${ }^{125}$ I content of the lysate were determined.

Adrenalectomy. SR-BI-null and control mice were adrenalectomized following standard surgical procedures (58). Following surgery, mice were placed in individual clean cages and allowed to recover for 1 week while maintained on normal chow diet and drinking water containing $0.9 \%$ sodium chloride. Sham-operated control mice underwent the same surgical procedure as adrenalectomized groups, except their adrenal glands were not excised. Experiments were performed 1 week after surgery. Sham-operated and test mice were injected i.p. with LPS and sacrificed 2 hours later.

Survival determination. $S R-B I^{-/-}$mice, $S R-B I^{+/-}$mice, and $S R-B I^{+/+}$mice were injected i.p. with $5 \mu \mathrm{g} / \mathrm{g}$ body weight of LPS. In some experiments, $S R-B I^{-/}$mice were given corticosterone (Sigma-Aldrich), initially dissolved in ethanol, in their drinking water $(100 \mu \mathrm{g} / \mathrm{ml})$ starting 8 hours prior to LPS injection. In these experiments, control groups were given an equivalent amount of vehicle only $(0.1 \%$ ethanol) in their drinking water. Mice were allowed to eat and drink freely. Mice were under careful observation for behavior and survival during the following 3 days.

Swim stress test and ACTH treatment. For the stress test, female mice were placed in $5^{\circ} \mathrm{C}$ water and forced to swim for 3 minutes (59). Following the swim, mice were rested at room temperature for 17 minutes prior to sacrifice. Blood was taken for corticosterone and ACTH determination. For ACTH treatment, mice were s.c. injected with the indicated amounts of ACTH (Questcor Pharmaceutical).
LPS clearance. SR-BI-null mice and control mice $(n=4)$ were injected with $0.125 \mu \mathrm{g} / \mathrm{g}$ body weight of ${ }^{125} \mathrm{I}$-LPS through tail veins. Mice were sacrificed after 30 minutes, and blood and tissue were collected for analysis. Plasma and tissue samples were weighed and counted in a $\gamma$ counter (Packard; PerkinElmer Life Inc). Tissue uptake was determined as described (3).

Statistics. Statistical comparison between control and the SR-BI-null animals within the same treatment group and between different treatment groups within the same genotype were carried out in each experiment, and all significant differences $(P<0.05)$ are given in the figures and/or figure legends. Statistical significance in experiments comparing only 2 groups was determined by 2 -tailed Student's $t$ test. The significance of the difference in mean values among more than 2 groups was evaluated by 1-way ANOVA, followed by post hoc analysis using Tukey's test. To determine statistical significance between survival curves, Kaplan-Meier log-rank test was used. All statistical analyses were done with GraphPad Prism 4 (GraphPad Software). Values are expressed as mean $\pm \mathrm{SD}$. A $P$ value of less than 0.05 was considered significant.

\section{Acknowledgments}

The authors would like to thank Xin Shi, Nathan Whitaker, and Scott Hensley for excellent technical support. We also thank Nancy R. Webb and Erik R.M. Eckhardt for useful suggestions. Funding was supported by NIH grants R01 HL63763 and P01 HL086670 (D. van der Westhuyzen) and University of Kentucky physicianscientist awards (L.R. Tannock).

Received for publication January 18, 2007, and accepted in revised form October 8, 2007.

Address correspondence to: Deneys R. van der Westhuyzen, Department of Internal Medicine, University of Kentucky, 541 CTW Health Science Building, 900 South Limestone Street, Lexington, Kentucky 40536, USA. Phone: (859) 323-4933 ext. 81397; Fax: (859) 257-3646; E-mail: dvwest1@uky.edu.
1. Russell, J.A. 2006. Management of sepsis. N. Engl.J. Med. 355:1699-1713.

2. Han, J., and Ulevitch, R.J. 2005. Limiting inflammatory responses during activation of innate immunity. Nat. Immunol. 6:1198-1205.

3. Rensen, P.C., et al. 1997. Human recombinant apolipoprotein $\mathrm{E}$ redirects lipopolysaccharide from Kupffer cells to liver parenchymal cells in rats in vivo. J. Clin. Invest. 99:2438-2445.

4. Pajkrt, D., et al. 1996. Antiinflammatory effects of reconstituted high-density lipoprotein during human endotoxemia. J. Exp. Med. 184:1601-1608.

5. Van Lenten, B.J., Fogelman, A.M., Haberland, M.E., and Edwards, P.A. 1986. The role of lipoproteins and receptor-mediated endocytosis in the transport of bacterial lipopolysaccharide. Proc. Natl. Acad. Sci. U. S. A. 83:2704-2708.

6. Wurfel, M.M., Kunitake, S.T., Lichenstein, H., Kane, J.P., and Wright, S.D. 1994. Lipopolysaccharide (LPS)-binding protein is carried on lipoproteins and acts as a cofactor in the neutralization of LPS. J. Exp. Med. 180:1025-1035.

7. Hampton, R.Y., Golenbock, D.T., Penman, M., Krieger, M., and Raetz, C.R. 1991. Recognition and plasma clearance of endotoxin by scavenger receptors. Nature. 352:342-344.

8. Van Amersfoort, E.S., Van Berkel, T.J., and Kuiper, J. 2003. Receptors, mediators, and mechanisms involved in bacterial sepsis and septic shock. Clin. Microbiol. Rev. 16:379-414.

9. Acton, S., et al. 1996. Identification of scavenger receptor SR-BI as a high density lipoprotein receptor. Science. 271:518-520.

10. Rigotti, A., Miettinen, H.E., and Krieger, M. 2003.
The role of the high-density lipoprotein receptor SR-BI in the lipid metabolism of endocrine and other tissues. Endocr. Rev. 24:357-387.

11. Fluiter, K., van der Westhuijzen, D.R., and van Berkel, T.J. 1998. In vivo regulation of scavenger receptor $\mathrm{BI}$ and the selective uptake of high density lipoprotein cholesteryl esters in rat liver parenchymal and Kupffer cells. J. Biol. Chem. 273:8434-8438.

12. Kozarsky, K.F., et al. 1997. Overexpression of the HDL receptor SR-BI alters plasma HDL and bile cholesterol levels. Nature. 387:414-417.

13. Cai, L., de Beer, M.C., de Beer, F.C., and van der Westhuyzen, D.R. 2005. Serum amyloid A is a ligand for scavenger receptor class B type I and inhibits high density lipoprotein binding and selective lipid uptake. J. Biol. Chem. 280:2954-2961.

14. Kapadia, S.B., Barth, H., Baumert, T., McKeating, J.A., and Chisari, F.V. 2007. Initiation of hepatitis $\mathrm{C}$ virus infection is dependent on cholesterol and cooperativity between CD81 and scavenger receptor B type I. J. Virol. 81:374-383.

15. Vishnyakova, T.G., et al. 2003. Binding and internalization of lipopolysaccharide by Cla-1, a human orthologue of rodent scavenger receptor B1. J. Biol. Chem. 278:22771-22780.

16. Vishnyakova, T.G., et al. 2006. CLA-1 and its splicing variant CLA- 2 mediate bacterial adhesion and cytosolic bacterial invasion in mammalian cells. Proc. Natl. Acad. Sci. U. S. A. 103:16888-16893.

17. Webb, N.R., et al. 1998. SR-BII, an isoform of the scavenger receptor $\mathrm{BI}$ containing an alternate cytoplasmic tail, mediates lipid transfer between high density lipoprotein and cells. J. Biol. Chem. 273:15241-15248.
18. Philips, J.A., Rubin, E.J., and Perrimon, N. 2005. Drosophila RNAi screen reveals CD36 family member required for mycobacterial infection. Science. 309:1251-1253.

19. Li, X.A., Guo, L., Asmis, R., Nikolova-Karakashian, M., and Smart, E.J. 2006. Scavenger receptor BI prevents nitric oxide-induced cytotoxicity and endotoxin-induced death. Circ. Res. 98:e60-e65.

20. Temel, R.E., et al. 1997. Scavenger receptor class B, type I (SR-BI) is the major route for the delivery of high density lipoprotein cholesterol to the steroidogenic pathway in cultured mouse adrenocortical cells. Proc. Natl. Acad. Sci. U. S. A. 94:13600-13605.

21. Stangl, H., Cao, G., Wyne, K.L., and Hobbs, H.H. 1998. Scavenger receptor, class B, type I-dependent stimulation of cholesterol esterification by high density lipoproteins, low density lipoproteins, and nonlipoprotein cholesterol. J. Biol. Chem. 273:31002-31008.

22. Swarnakar, S., Temel, R.E., Connelly, M.A., Azhar, S., and Williams, D.L. 1999. Scavenger receptor class B, type I, mediates selective uptake of low density lipoprotein cholesteryl ester. J. Biol. Chem. 274:29733-29739.

23. Kovanen, P.T., Schneider, W.J., Hillman, G.M., Goldstein, J.L., and Brown, M.S. 1979. Separate mechanisms for the uptake of high and low density lipoproteins by mouse adrenal gland in vivo. J. Biol. Chem. 254:5498-5505.

24. Andersen, J.M., and Dietschy, J.M. 1978. Relative importance of high and low density lipoproteins in the regulation of cholesterol synthesis in the adrenal gland, ovary, and testis of the rat. J. Biol. Chem. 253:9024-9032. 
25. Kraemer, F.B. 2007. Adrenal cholesterol utilization. Mol. Cell. Endocrinol. 265-266:42-45.

26. Allen, J.M., Thompson, G.R., and Myant, N.B. 1983. Normal adrenocortical response to adrenocorticotrophic hormone in patients with homozygous familial hypercholesterolaemia. Clin. Sci. (Lond.) 65:99-101.

27. Franchimont, D. 2004. Overview of the actions of glucocorticoids on the immune response: a good model to characterize new pathways of immunosuppression for new treatment strategies. Ann. N. Y. Acad. Sci. 1024:124-137.

28. Annane, D., Bellissant, E., and Cavaillon, J.M. 2005. Septic shock. Lancet. 365:63-78.

29. Miller, W.L. 2007. StAR search--what we know about how the steroidogenic acute regulatory protein mediates mitochondrial cholesterol import. Mol. Endocrinol. 21:589-601.

30. Plump, A.S., et al. 1996. Apolipoprotein A-I is required for cholesteryl ester accumulation in steroidogenic cells and for normal adrenal steroid production. J. Clin. Invest. 97:2660-2671.

31. Rigotti, A., et al. 1997. A targeted mutation in the murine gene encoding the high density lipoprotein (HDL) receptor scavenger receptor class B type I reveals its key role in HDL metabolism. Proc. Natl. Acad. Sci. U. S. A. 94:12610-12615.

32. Gu, X., et al. 1998. The efficient cellular uptake of high density lipoprotein lipids via scavenger receptor class B type I requires not only receptormediated surface binding but also receptor-specific lipid transfer mediated by its extracellular domain. J. Biol. Chem. 273:26338-26348.

33. Davies, E., and MacKenzie, S.M. 2003. Extra-adrenal production of corticosteroids. Clin. Exp. Pharmacol. Physiol. 30:437-445.

34. Gonzalez, J.C., et al. 1993. Endogenous and exogenous glucocorticoids have different roles in modulating endotoxin lethality in D-galactosamine-sensitized mice. Infect. Immun. 61:970-974.

35. Le, T., and Schimmer, B.P. 2001. The regulation of MAPKs in Y1 mouse adrenocortical tumor cells. Endocrinology. 142:4282-4287.

36. Goldstein, J.L., DeBose-Boyd, R.A., and Brown, M.S. 2006. Protein sensors for membrane sterols. Cell. 124:35-46.

37. Cummins, C.L., et al. 2006. Liver X receptors reg- ulate adrenal cholesterol balance. J. Clin. Invest. 116:1902-1912.

38. Braun, A., et al. 2003. Probucol prevents early coronary heart disease and death in the high-density lipoprotein receptor SR-BI/apolipoprotein E double knockout mouse. Proc. Natl. Acad. Sci. U. S. A. 100:7283-7288.

39. Prigent, H., Maxime, V., and Annane, D. 2004. Science review: mechanisms of impaired adrenal function in sepsis and molecular actions of glucocorticoids. Crit. Care. 8:243-252.

40. Azhar, S., and Reaven, E. 2002. Scavenger receptor class BI and selective cholesteryl ester uptake: partners in the regulation of steroidogenesis. Mol. Cell. Endocrinol. 195:1-26.

41. Connelly, M.A., Kellner-Weibel, G., Rothblat, G.H., and Williams, D.L. 2003. SR-BI-directed HDL-cholesteryl ester hydrolysis. J. Lipid Res. 44:331-341.

42. Out, R., et al. 2004. Scavenger receptor class B type I is solely responsible for the selective uptake of cholesteryl esters from HDL by the liver and the adrenals in mice. J. Lipid Res. 45:2088-2095.

43. Stangl, H., Graf, G.A., Yu, L., Cao, G., and Wyne, K. 2002. Effect of estrogen on scavenger receptor BI expression in the rat. J. Endocrinol. 175:663-672.

44. Khovidhunkit, W., Moser, A.H., Shigenaga, J.K., Grunfeld, C., and Feingold, K.R. 2001. Regulation of scavenger receptor class B type I in hamster liver and Hep3B cells by endotoxin and cytokines. J. Lipid Res. 42:1636-1644.

45. Buechler, C., Ritter, M., Quoc, C.D., Agildere, A., and Schmitz, G. 1999. Lipopolysaccharide inhibits the expression of the scavenger receptor Cla-1 in human monocytes and macrophages. Biochem. Biophys. Res. Commun. 262:251-254.

46. Cabana, V.G., Siegel, J.N., and Sabesin, S.M. 1989 Effects of the acute phase response on the concentration and density distribution of plasma lipids and apolipoproteins. J. Lipid Res. 30:39-49.

47. Ulevitch, R.J., and Johnston, A.R. 1978. The modification of biophysical and endotoxic properties of bacterial lipopolysaccharides by serum. J. Clin. Invest. 62:1313-1324.

48. Bocharov, A.V., et al. 2004. Targeting of scavenger receptor class B type I by synthetic amphipathic alpha-helical-containing peptides blocks lipopolysaccharide (LPS) uptake and LPS-induced pro-inflammatory cytokine responses in THP-1 monocyte cells. J. Biol. Chem. 279:36072-36082.

49. Titheradge, M.A. 1999. Nitric oxide in septic shock. Biochim. Biophys. Acta. 1411:437-455.

50. Van Eck, M., et al. 2003. Differential effects of scavenger receptor BI deficiency on lipid metabolism in cells of the arterial wall and in the liver. J. Biol. Chem. 278:23699-23705.

51. Covey, S.D., Krieger, M., Wang, W., Penman, M., and Trigatti, B.L. 2003. Scavenger receptor class B type I-mediated protection against atherosclerosis in LDL receptor-negative mice involves its expression in bone marrow-derived cells. Arterioscler. Thromb. Vasc. Biol. 23:1589-1594.

52. Braun, A., et al. 2002. Loss of SR-BI expression leads to the early onset of occlusive atherosclerotic coronary artery disease, spontaneous myocardial infarctions, severe cardiac dysfunction, and premature death in apolipoprotein E-deficient mice. Circ. Res. 90:270-276.

53. Boring, L., Gosling, J., Cleary, M., and Charo, I.F. 1998. Decreased lesion formation in CCR2 ${ }^{-/-}$mice reveals a role for chemokines in the initiation of atherosclerosis. Nature. 394:894-897.

54. Hansson, G.K., and Libby, P. 2006. The immune response in atherosclerosis: a double-edged sword. Nat. Rev. Immunol. 6:508-519.

55. Stuart, L.M., et al. 2005. Response to Staphylococcus aureus requires CD36-mediated phagocytosis triggered by the $\mathrm{COOH}$-terminal cytoplasmic domain. J. Cell Biol. 170:477-485.

56. Ulevitch, R.J. 1978. The preparation and characterization of a radioiodinated bacterial lipopolysaccharide. Immunochemistry. 15:157-164.

57. Horton, J.D., Shimano, H., Hamilton, R.L., Brown, M.S., and Goldstein, J.L. 1999. Disruption of LDL receptor gene in transgenic SREBP-1a mice unmasks hyperlipidemia resulting from production of lipid-rich VLDL. J. Clin. Invest. 103:1067-1076.

58. Hoffman-Goetz, L., Quadrilatero, J., Boudreau, J., and Guan, J. 2004. Adrenalectomy in mice does not prevent loss of intestinal lymphocytes after exercise. J. Appl. Physiol. 96:2073-2081.

59. Smythe, G.A., Bradshaw, J.E., and Vining, R.F. 1983. Hypothalamic monoamine control of stressinduced adrenocorticotropin release in the rat. Endocrinology. 113:1062-1071. 